\title{
Point-of-care testing in the cardiovascular operating theatre
}

\author{
Urs E. Nydegger*, Erich Gygax and \\ Thierry Carrel \\ University Clinic for Cardiovascular Surgery, \\ Inselspital Bern, Bern, Switzerland
}

\begin{abstract}
Point-of-care testing (POCT) remains under scrutiny by healthcare professionals because of its ill-tried, young history. POCT methods are being developed by a few major equipment companies based on rapid progress in informatics and nanotechnology. Issues as POCT quality control, comparability with standard laboratory procedures, standardisation, traceability and round robin testing are being left to hospitals. As a result, the clinical and operational benefits of POCT were first evident for patients on the operating table. For the management of cardiovascular surgery patients, POCT technology is an indispensable aid. Improvement of the technology has meant that clinical laboratory pathologists now recognise the need for POCT beyond their high-throughput areas.

Clin Chem Lab Med 2006;44:1060-5.
\end{abstract}

Keywords: blood gas; cardiotechnician; coagulation; extracorporeal bypass; haematocrit; heart surgery; point-of-care testing; thrombelastogram.

\section{Introduction}

A current trend in laboratory medicine is to perform patient tests near to the point at which care is rendered, commonly referred to as point-of-care testing (POCT). POCT procedures can take place in various locations, such as in the patient's home, pharmacies, the physician's office, and satellite laboratories (kiosks) in the emergency department of hospitals (1, 2 ) as well as in operating theatres of various surgical specialties. In mainland China, POCT has become popular (3). The healthcare industry is currently focusing on analytical equipment in the POCT setting, with the development of clinical laboratory instrumentation and reagents for performing clinical chemistry tests (www.researchandmarkets.com, www.made-inchina.com).

The present summary is an analysis of the proficiency of POCT during heart surgery. Mobile laboratory analysers in the operating room have become an

* Corresponding author: Urs E. Nydegger, MD,

Praxis Dr. H.G. Walther, Hirschengraben 10,

3011 Bern, Switzerland

Phone: +41-31-3812565, Fax: +41-31-3811083,

E-mail: info@immune-complex.ch integral part of the equipment needed for state-of-theart perioperative management of heart surgery patients, especially those on extracorporeal blood circulation (ECC). Using POCT, the pre-analytical step for optimised storage of blood samples has become irrelevant because of the advantage of immediate testing. However, determining the best drawing site, i.e., from catheters or from extracorporeal circuitry tubing or its built-in stopcocks, remains a relevant consideration $(4,5)$. POCT of blood cells might feature ECC systemspecific red blood cell (RBC) and/or platelet alterations (6). Guidelines and suggestions for specimen collection from indwelling catheters or cannulae have been put forward by the International Federation of Clinical Chemistry and Laboratory Medicine (IFCC). In Europe, the register for specialties in clinical chemistry and laboratory medicine EC4 now comprises approximately 1500 specialists in this field, with increasing concern being expressed regarding POCT quality (7). POC diagnosis (POCD), complemented by POC monitoring (POCM), has been suggested as a means of improving the capacity of anaesthetists and cardiotechnicians to react appropriately in the case of abnormal laboratory values. The need for establishing evidence-based POCT practice is now covered by the National Academy of Clinical Chemistry (NACB) guidelines (www.nacb.org/lmpg/poct_LMPG_draft word.stm). Although it is becoming more widely accepted, POCT is still often under the scrutiny of regular clinical pathology laboratory staff (8). Inadequate monitoring of quality controls, as well as economic aspects, have been put forward as arguments for avoiding POCT. On the contrary, those in favour of POCT focus on the increased efficiency and availability of test results, which allow therapeutic decisions without delay, an aspect that is most crucial for the care of cardiovascular surgery patients.

\section{Coagulation}

POCT-supported procedures, such as preparation of autologous fibrinogen and platelets, depend on coagulation tests (Table 1). There are two methods currently in use: activated clotting time and in special cases thrombelastography (TEG).

\section{Activated clotting time (ACT)}

During the use of oxygenator and filters and their associated surfaces for ECC, high levels of heparin are required to maintain blood in a fluid state (typically 2.0-4.0 U/mL). In the early days of cardiac surgery, 
Table 1 Random choice of instruments and assays for monitoring anticoagulants in cardiopulmonary bypass in a POCT setting.

\begin{tabular}{lll}
\hline Instrument & Assay & Bias \\
\hline Hemochron ${ }^{\circledR}$ Response & $\begin{array}{l}\text { Prothrombin time (PT) and activated } \\
\text { partial thromboplastin time (APTT) } \\
\text { Activated clotting time }\end{array}$ & $\begin{array}{l}\text { During bypass acceptable, after bypass } \\
\text { questionable (9) } \\
\text { Heparin }\end{array}$ \\
$\begin{array}{l}\text { HemoTec } \\
\text { ACT Plus }{ }^{\text {TM }} \text { automated coagulation }\end{array}$ & & Heparin \\
timer system & Heparin management test & Thrombin inhibitors \\
$\begin{array}{l}\text { TAS analyser (10) } \\
\text { TAS analyser }\end{array}$ & Ecarin clotting time & Aspirin, gpllb/llla inhibitors \\
$\begin{array}{l}\text { Platelet function analyser } \\
\text { Thrombelastograph }\end{array}$ & Platelet function & Aspirin, gpllb/llla inhibitors, aprotinin \\
Hepcon & Clot signature and platelet function & Protamine \\
\hline $\begin{array}{l}\text { a Two instruments for which the producer proposes measurement of the same parameters cannot necessarily be used inter- } \\
\text { changeably (11). }\end{array}$ &
\end{tabular}

the dose of heparin required and its reversal with protamine were calculated using a formula. The problem with such a mathematical rule was that the doses calculated could not predict the individual patient's reaction to heparin, which can vary by as much as $20-35 \%$. Therefore, as early as 1966, the activated clotting time was developed by Hattersley (12) and a dosing scheme based on the 480-s target time was established. The test is performed in a hand-held glass tube, which is periodically inverted. The start and end of heparinisation, which is reversed by protamine, are timed between cannulation of the aorta and the right atrium using an average dosage of $400 \mathrm{U}$ heparin $/ \mathrm{kg}$ body weight. The side effects of ECC, as a result of the limited biocompatibility of the circuitry's artificial surfaces (13), include activation of the complement and fibrinolytic systems.

In 1988, Hemochron released the first automated ACT device. Pre-operative testing with an ACT device effectively identifies the patient's reaction to heparin so that overdosing and/or underdosing during surgery can be avoided. Accurate ACT POCT reduces postoperative blood loss and the requirement for transfusion of RBCs, platelet concentrate and fresh frozen plasma (14). Therefore, protamine use and reexploration for non-specific surgical bleeding can be reduced to a minimum.

Because ACT has become the gold standard for monitoring heparin during ECC, its success has led to the development of a series of alternative assays based on the same concept. Usually these assays are performed with different instrumentation and with celite or kaolin as the coagulation activator. Each commercial activator initiates factor XII activation in a different manner, so the various ACTs may have different sensitivities and specificities.

Factors that are directly related to heart surgery can influence ACT (15). In fact, the widespread use of fibrinolysis inhibitors such as aprotinin and $\varepsilon$-aminocaproic acid (16) has made it necessary to keep track of their activity using POCT. Linear regression and error analysis were used to compare POCT devices with standard laboratory methods (9) and the comparison showed favourable results for POCT. Furthermore, patients with infectious endocarditis, surgery on the thoracic aorta using hypothermia (17) and selective circulation arrest, or patients with prior heparinisation need to be continuously monitored using ACT.

POCT instruments that monitor patients treated with vitamin $\mathrm{K}$ antagonists are not useful in the operating theatre; the accuracy of these instruments has recently been reviewed elsewhere $(18,19)$. For POCT in the operating theatre or the paediatric cardiac intensive care unit, a number of instruments from different producers are on the market (20-22).

\section{Thrombelastography (TEG)}

Modern TEG machines electronically identify the process of clot formation from the initial point of fibrin formation and platelet aggregation until the clot is lysed (23).

TEG may be useful during aortic surgery or when a balloon is inserted into the aorta to complement insufficient cardiac output or to initiate the function of an artificial heart. In addition, the side effects of ECC components caused by roller pumps, centrifugal pumps, axial pumps and other devices can be monitored by POCT, including TEG, and can be immediately corrected if necessary.

In our clinic we use the Roteg analyser (Axon Lab AG, Zurich, Switzerland). In contrast to conventional TEG, the Roteg system works based on the addition of activators and inhibitors of coagulation, and thus allows for differential measurement of platelet function. Impedance-based measurements of platelet aggregation might extend the diagnostic spectrum to exploration of specific platelet functions. Cardiac surgery patients often undergo substantial haemodilution, resulting in intraoperative haematocrit values between 0.15 and 0.20 . We have recently found when using RoTEM ${ }^{\circledR}$ (Pentapharm, Munich, Germany) that hydroxyethlystarch (HES, Voluven ${ }^{\circledR}$; Fresenius Kabi, Stans, Switzerland) impairs the coagulation system more than saline or Ringer-lactate solution does when used for volume replacement (24). Surgical interventions that require hypothermia, with body temperatures between $18^{\circ} \mathrm{C}$ and $22^{\circ} \mathrm{C}$, need POCT TEG monitoring of platelet function. Recently, TEG has been used for the reversal of heparin effects based on 
the addition of heparinase to the reagent cup, whereby the contribution of hyperfibrinolysis to clot decomposition becomes readily apparent. In these cases, the diagnostic value of TEG depends on the contact activator used: differential usage of ellagic acid tissue factor in drawing diagnostic conclusions becomes possible (25), thereby reducing transfusion requirements $(26,27)$. POCT TEG results can be used to determine the prescription of costly recombinant factor VIIa (rFVIIA) to counterbalance HES-induced dilutional coagulopathy.

\section{Electrolytes and blood gases}

The patient's ventilation status is monitored by electrolyte, blood gas analysis (BGA) and $\mathrm{pH}$ measurements and is evaluated during and immediately after heart surgery. Such equipment is also found as POCT devices in respiratory laboratories. In cardiac surgery, electrolytes are predominantly measured to control the performance of artificial lung oxygenators. With the development of more complex surgical interventions, such as those in which the complete thoracicabdominal aorta down to the aorto-iliacal bifurcation is replaced, control of visceral and peripheral perfusion is mandatory. Similarly, the influence of vasoactive drugs and other anaesthetic interventions can be continuously controlled using POCT BGA measurements.

\section{Electrolytes}

In operations on a resting heart, a potassium-enriched blood-cardioplegic solution is infused every $20 \mathrm{~min}$ into the coronary arterial circuitry; such myocardial protection prevents the occurrence of uncontrolled ischaemia during cardiac arrest. The infusion of this solution may lead to myocardial, and sometimes even systemic hyperkalaemia, which may result in arrythmias that are difficult to control. Measurement of serum potassium concentrations immediately after infusion of the potassium-enriched solution is therefore important for the immediate correction of kalaemia. Avalanche and drowning victims usually present with hyperkalaemia, with prognosis based on the degree and speed of correction of such hyperkalaemia. For avalanche victims, POCT BGA (see below) is performed to distinguish wet snow from powder snow. The former implies poorer prognosis, since the asphyxia resembles drowning, with decreased $\mathrm{pO}_{2}$ and increased $\mathrm{pCO}_{2}$ followed by cardiac arrest, whereas victims of powder snow are subject to hibernation, which is likely to be treatable once the victim is re-warmed using ECC, much as for cardiac surgery (28). In newborns undergoing heart surgery, serum potassium is important and hyperkalaemia is usually caused by transfusing RBCs stored for more than 10 days after donation. In these cases, serum potassium levels need to be monitored at the operating table and corrected, if necessary, by insertion of a haemodialysis filter into the ECC. Other interventions that require tight potassium control are regional perfusion treatments in the case of acute obstruction of a lower limb or in severe acidosis (Leriche syndrome). Lung arterial thrombendectomies or operations performed in deep hypothermic cardiac arrest, such as for replacement of the aorta ascendens, aortic arch and aorta abdominalis, depend on POCT. Cardioplegia performed with autologous blood is carried out with hyperkalaemic sodium chloride mixed with blood 1:4, whereas the pure hyperkalaemic solution does not contain blood. Upon passage through the coronaries, these solutions reach the right atrium and become mixed with the patient's whole blood volume. With crystalloid cardioplegia, a large infusion volume of 2000 to $3000 \mathrm{~mL}$ is infused which leads to severe hyponatraemia ( $<120 \mathrm{mmol} / \mathrm{L})$.

Correction of hyponatraemia, especially in transplant recipients, is slow and constantly monitored using POCT, as sodium levels need to be closely controlled. In fact, we control sodium levels until the end of ECC and then return them to preoperative values. Using such a strategy, postoperative patient consciousness can also improve (avoidance of postperfusion syndrome).

Determining the sodium concentration remains an important diagnostic tool for monitoring possible anaphylactic side effects. Differential diagnosis between idiopathic vasoplegia, anaphylactic reaction towards plasma expanders, and transfusion-related acute lung injury (TRALI) by administration of fresh frozen plasma (29) and/or drugs (aprotinin), under ECC conditions is difficult. Preoperative sodium measurements are important in the case of intercurrent haematocrit increase (extravasal volume shift), which may truly reflect anaphylactic reaction and needs to be treated with large volume substitution, noradrenalin and corticosteroids. Calcium and magnesium ion concentrations should be maintained at preoperative levels throughout the intervention and therefore need to be continuously measured by POCT with the aim of maintaining optimal conditions for normal myocardial contractility and regular rhythm postoperatively.

\section{Blood gas analysis}

The most vital laboratory parameters during open heart surgery are routine $\mathrm{BGAs}$, which include repeated measurements of $\mathrm{pO}_{2}, \mathrm{pCO}_{2}, \mathrm{HCO}^{3-}, \mathrm{pH}$ and base excess. In leading clinics, blood gases are continuously monitored, allowing response to diagnostic, therapeutic and prognostic criteria. In addition to electrolytes, BGA allows estimation of the patient's condition and the efficacy of $\operatorname{ECC}(2,30)$ by the measurement of central mixed venous $\mathrm{pO}_{2}$ saturation. Since as a rule all heart surgery procedures are performed under either moderate $\left(32^{\circ} \mathrm{C}\right)$ or, in special cases, deep $\left(20^{\circ} \mathrm{C}\right)$ hypothermia, $B G A$ is of special interest. Upon installation of hypothermia two strategies are pursued: 
1. The alphastat value, based on maintaining noncorrected $\mathrm{pH} 7.40$ and $\mathrm{pCO}_{2}$ of $40 \mathrm{~mm} \mathrm{Hg}$ measured at $37^{\circ} \mathrm{C}$. Such a strategy ensures constant relative respiratory alkalosis by maintaining $\mathrm{CO}_{2}$ content and a constant $\mathrm{H}^{+} / \mathrm{OH}^{-}$ratio in the blood, which simulates poikilothermia. The degree to which key plasma proteins such as highly active enzymes are ionised is important for their functional performance. The true $\mathrm{pH}$ value of arterial blood decreases by $0.0147 \mathrm{pH}$ units for each $1^{\circ} \mathrm{C}$ increase in body temperature. Thus, a reduction in body temperature by $10^{\circ} \mathrm{C}$ will lead to a relevant increase in $\mathrm{pH}$ of 0.15 . In contrast, $\mathrm{O}_{2}$ and $\mathrm{CO}_{2}$ decrease. To reach alphastat during hypothermic ECC, relative hyperventilation must be maintained (30).

2. The $\mathrm{pH}$-stat value, based on maintaining $\mathrm{pH} 7.40$ and $\mathrm{pCO}_{2}$ of $40 \mathrm{~mm} \mathrm{Hg}$ at true rectal temperature corrected to $37^{\circ} \mathrm{C}$. Such a strategy maintains that normal $\mathrm{pH}$ values of 7.40 and $\mathrm{pCO}_{2}$ of $40 \mathrm{~mm} \mathrm{Hg}$ at $37^{\circ} \mathrm{C}$ are also measured during hypothermia. Relative respiratory acidosis then occurs, whereby the acid-base equilibrium simulates hibernation. To reach $\mathrm{pH}$-stat during ECC, relative hypoventilation and the addition of $\mathrm{CO}_{2}$ to the gas mixture for the artificial lung are necessary. New developments are focusing on displacement of air from the heart chambers by controlling the inflow of the denser $\mathrm{CO}_{2}$. Such a deaeration procedure affects the blood gas profile, and thus immediately controlled POCT BGA is indispensable for patient monitoring.

\section{Haematocrit}

Besides BGA, haematocrit is controlled regularly every $20 \mathrm{~min}$; appropriate $\mathrm{O}_{2}$ supply is linked to blood gas physiology, as well as to $\mathrm{O}_{2}$ transport capacity. The $\mathrm{O}_{2}$-dissociation curve must be maintained within physiological limits as best as possible under ECC conditions using an artificial lung. Should the $\mathrm{O}_{2}$ supply fail, lack of $\mathrm{O}_{2}$ in the terminal tissue could lead to cerebral ischaemia and, in some cases, cerebral hypoxia, which could result in oedema and/or the development of microemboli.

In addition to controlling hypothermia, the haematocrit and BGA also serve as a general surveillance of the patient and of the function of the ECC machine. Thus, failure of an artificial lung or various low-perfusion situations, e.g., cannulation of the wrong lumen on aortic dissection, can be recognised and immediately corrected. If the intraoperative haematocrit value falls too low, blood transfusion, most likely with RBC concentrates, becomes necessary, which is referred to as a transfusion trigger (31).

\section{Expert opinion}

We conclude that without POCT, state-of-the-art heart surgery is not possible. Just as critically ill patients in the ICU require laboratory results in real time, those on the operating table of a cardiac surgeon depend on immediate results of laboratory tests. There are three main sources of errors: operator incompetence, use of uncontrolled reagents and non-adherence to test procedures. The likelihood that such errors affect outcomes can be amplified by rapid POCT results followed by immediate, imprudently prescribed therapy $(32,33)$. As yet, POCT is not perfect. Additional POCT improvements in the operating theatre will require versatile instruments that have the same accuracy as the instrumentation used in clinical pathology laboratories. Quality maintenance involving regular testing of blinded controls and documented results is necessary to meet quality control requirements. POCT must be subject to local, national and international ISO-certified round robin testing (34). Communication between technicians in the operating theatre and central laboratory pathologists is required (35). The safety of POCT is also dependent on the training of the healthcare professionals who perform the tests. In certain countries, task forces are at work that are controlled by Committees for Standards. A recent questionnaire issued to several hundred participants targeted such professionals as nurses, laboratory scientists, pharmacists and general practitioners (36). In addition to internal quality control, we advocate similar control mechanisms to be issued for anaesthetists and cardiotechnicians who care for heart surgery patients (37). The cardiotechnician's job description should include monitoring of vital parameters with analysis of basic haematology and clinical chemistry. The University of Texas now tests their employees for proficiency using an intranet-type questionnaire (http://www.utmb.edu/poc/online.htm).

The values obtained by POCT need to be documented in the patient's history, i.e., on an electronic health record (EHR) spreadsheet with traceability, so that they can be referred to during the patient's perioperative care. At our hospital, laboratory rules, in effect, focus on quality control, with constant and reproducible criteria for the equipment of the permanent clinical pathology laboratory as well as the POCT service. These rules also relate to the overall strategy of the hospital, as well as health insurance and care standards. A permanent expert group is responsible for assuring quality control.

\section{Outlook}

The direction of POCT in the operating theatre should evolve on four tracks. (i) Industry should design integrated POCT diagnostic equipment suited to the needs of the operating theatre for the most important surgical disciplines, such as cardiothoracic, orthopaedic, neurological and visceral surgery. (ii) Cost-effectiveness, ease of use, user accuracy and precision criteria for test results should be further developed. Users, if not primarily trained as laboratory technicians, should have to pass licensing tests. (iii) POCTspecific regulations and guidelines for quality control 
procedures should be recommended and implemented on an international level. (iv) Local partnerships between laboratory professionals, surgeons, anaesthetists and cardiotechnicians should be developed.

\section{Highlights}

POCT is essential in following up cardiovascular surgery patients in the operating theatre. POCT needs to be fully approved by clinical laboratory specialists not present during the operation. Instead of competing with non-licensed personnel, trained laboratory personnel need to instruct and organise teaching events for anaesthetists and cardiotechnicians. Round robin testing must bring POCT results to the level of international comparable laboratory results generated in the operation theatre. Standard preparations sent around the globe should be measured with POCT equipment and made available for EHR tracing.

\section{Acknowledgements}

The authors are indebted to Benz Wermuth, PhD, Director of the Central Clinical Pathology Laboratory, University of Bern, for advice and to Deborah Stroka, PhD, Director of R\&D at the University Clinic for Visceral Surgery, Bern, for revision of the English.

\section{References}

1. Lee-Lewandrowski E, Corboy D, Lewandrowski K, Sinclair J, McDermot S, Benzer TI. Implementation of a point-ofcare satellite laboratory in the emergency department of an academic medical center. Impact on test turnaround time and patient emergency department length of stay. Arch Pathol Lab Med 2003;127:456-60.

2. Lewandrowski K. How the clinical laboratory and the emergency department can work together to move patients through quickly. Clin Leadersh Manage Rev 2004;18:155-9.

3. Zhang WZ. Current situation of clinical chemistry in mainland China. Clin Chem Lab Med 2000;38:1315-6.

4. Hill AB, Nahrwold ML, Noonan D, Northrop P. A comparison of methods of blood withdrawal and sample preparation for potassium measurements. Anaesthesiology 1980;53:606-63.

5. Burnett RW, Covington AK, Fogh-Andersen N, Kulpman WR, Maas AH, Muller-Plathe $\mathrm{O}$. Recommendations on whole blood sampling, transport, and storage for simultaneous determination of $\mathrm{pH}$, blood gases, and electrolytes. International Federation of Clinical Chemistry Scientific Division. J Int Fed Clin Chem 1994;6:115-20.

6. Borgdorff $P$, van den Berg RH, Vis MA, van den Bos GC, Tangelder GJ. Pump-induced platelet aggregation in albumin-coated extracorporeal systems. J Thorac Cardiovasc Surg 1999;118:946-52.

7. Sanders G, Opp M, McMurray J, Koeller U, Blaton V, Lund $\mathrm{E}$, et al. The European Register for specialists in Clinical Chemistry and Laboratory Medicine: code of conduct. Clin Chem Lab Med 2004;42:563-5.

8. Stief TW, Fareed J. Point of care: diagnostics in hemostasis - the wrong direction? Clin Appl Thromb Hemost 2003;9:191-5.
9. Choi TS, Greilich PE, Shi C, Wilson JS, Keller A, Kroll $\mathrm{MH}$. Point-of-care testing for prothrombin time, but not activated partial thromboplastin time, correlates with laboratory methods in patients receiving aprotinin or epsilon-aminocaproic acid while undergoing cardiac surgery. Am J Clin Pathol 2002;117:74-8.

10. Ambrose TM, Parvin CA, Mendeloff E, Luchtman-Jones L. Evaluation of the TAS analyzer and the low-range heparin management test in patients undergoing extracorporeal membrane oxygenation. Clin Chem 2001;47: 858-66.

11. Avendano A, Ferguson JJ. Comparison of Hemochron and HemoTex activated coagulation time target values during percutaneous transluminal coronary angioplasty. J Am Coll Cardiol 1994;23:803-4.

12. Piffare R. Management of bleeding in cardiovascular surgery. Philadelphia, PA: Hanley \& Belfus, 2000.

13. Berdat PA, Gygax E, Nydegger UE, Carrel T. Short- and long-term mechanical cardiac assistance. Int J Artif Organs 2001;24:263-73.

14. Nydegger U. Transfusion dependency of cardiovascular surgery - update 2005. Swiss Med Wkly. Revision submitted.

15. Svenmarker S, Appelblad M, Jansson E, Haggmark S. Measurement of the activated clotting time during cardiopulmonary bypass: differences between Hemotec ACT and Hemochron Jr apparatus. Perfusion 2004;19: 289-94.

16. Dobkowski WB, Murkin JM. A risk-benefit assessment of aprotinin in cardiac surgical procedures. Drug Saf 1998; 18:21-41.

17. Kmiecik SA, Liu JL, Vaadia TS, Nichols JD, Kohtz RJ, Mills NJ, et al. Quantitative evaluation of hypothermia, hyperthermia, and hemodilution on coagulation. J Extra Corpor Technol 2001;33:100-5.

18. Khoschnewis S, Hannes FM, Tschopp M, Wuillemin WA. INR comparison between the CoaguChek Pro PT(N) and a standard laboratory method. Thromb Res 2004;113: 327-32.

19. Dorfman DM, Goonan EM, Beutilier MK, Jarolim P, Tanasijevica M, Goldhaber SZ. Point-of-care (POC) versus central laboratory instrumentation for monitoring oral anticoagulation. Vasc Med 2005;10:23-7.

20. Faraday N, Guallar E, Sera VA, Bolton ED, Scharpf RB, Cartarius AM, et al. Utility of whole blood hemostatometry using the clot signature analyzer for assessment of hemostasis in cardiac surgery. Anesthesiology 2002; 96:1115-22.

21. Johi RR, Cross MH, Hansbro SD. Near-patient testing for coagulopathy after cardiac surgery. Br J Anaesth 2003; 90:499-501.

22. Rossi AF, Khan D. Point of care testing: improving pediatric outcomes. Clin Biochem 2004;37:456-61.

23. Royston D, von Kier S. Reduced haemostatic factor transfusion using heparinase modified thrombelastography during cardiopulmonary bypass. Br J Anaesth 2001; 86:575-8.

24. Kessler U, Jenni HJ, Zosso A, Zachariou Z, Nydegger U. Impact of haemodilution solutions on thrombelastography (TEG). Haemostaseologie 2006;26:A26-7.

25. Engstrom M, Reinstrup P, Schott $U$. An in vitro evaluation of standard rotational thrombelastography in monitoring of effects of recombinant factor VIla on coagulopathy induced by hydroxyethyl starch. BMC Blood Disord 2005;5:3.

26. Sorensen ER, Lorme TB, Heath D. Thrombelastography: a means to transfusion reduction. Nurs Manage 2005;36: 27-33.

27. Despotis GJ, Joist JH, Goodnough LT. Monitoring of hemostasis in cardiac surgical patients: impact of pointof-care testing on blood loss and transfusion outcomes. Clin Chem 1997;43:1684-96. 
28. Farstad M, Andersen KS, Koller ME, Grong K, Sagadal L, Husby P. Rewarming from accidental hypothermia by extracorporeal circulation. A retrospective study. Eur J Cardiothorac Surg 2001;20:59-64.

29. Bux J. Transfusion-related acute lung injury (TRALI): a serious adverse event of blood transfusion. Vox Sang 2005;89:1-10.

30. Preusse CJ, Schulte HD. Extrakorporale Zirkulation heute. Darmstadt: Steinkopff Verlag, 1991.

31. Hardy JF. Current status of transfusion triggers for red blood cell concentrates. Transfus Apheresis Sci 2004;31: 55-66.

32. Meier FA, Jones BA. Point-of-care testing error: sources and amplifiers, taxonomy, prevention strategies, and detection monitors. Arch Pathol Lab Med 2005;129: 1262-7.

33. Kost GJ. Preventing medical errors in point-of-care testing: security, validation, safeguards, and connectivity. Arch Pathol Lab Med 2001;125:1307-15.
34. Queralto JM. The EC4 quality manual model. Clin Chim Acta 2001;309:127-36.

35. Di Serio F, Amodio G, Varraso L, Campaniello M, Coluccia $P$, Trerotoli $P$, et al. Integration between point-of-care cardiac markers in an emergency/cardiology department and the central laboratory: methodological and preliminary clinical evaluation. Clin Chem Med Lab 2005; 43:202-9.

36. Kitchen DP, Kitchen S, Jennings I, Woods TA, Walker ID, Preston FE. Point of care testing by health care professionals: current practice amongst the UK National External Quality Assessment Scheme Participants. $\mathrm{Br} \mathrm{J}$ Haematol 2005;130:318-21.

37. Collison B. An academic degree doesn't always mean better bedside care. RN 2005;68:12-14.

Received November 9, 2005, accepted May 31, 2006 